\title{
REVIEWS
}

\section{THE BIOLOGY OF MAN}

BIOLOGICAL ASPECTS OF SOCIAL PROBLEMS. Edited by J. E. Meade and A. S. Parkes. Oliver and Boyd, Edinburgh and London, 1965. Pp. $x+226.50$ s.

This volume is an account of the Eugenics Society Symposium held in London in October 1964 . It contains the papers presented at the meetings, together with a heavily censored account of the subsequent discussion. The meeting was an attempt to bring together biologists, geneticists, sociologists, demographers and economists, so that they could interchange their ideas to their mutual benefit. The papers were presented in four sectionspopulation trends, social mobility and education, genetic aspects of medicine and aspects of fertility control.

This volume suffers from the defect inherent in all such books; each paper is an account of a particular piece of work and stands by itself. Thus, despite the efforts of the organisers of the symposium and the editors, there is no clear theme running through the book. It is no better than a neatly bound bundle of offprints. Having said this, it must be made clear that the papers themselves are of a high standard and well worth possessing. The reviewer found many of the papers quite fascinating and the book helped to pass the time flying from Geneva to Bangkok most pleasantly. This collection of papers is an important contribution to our understanding of the biology of man.

P. M. ShePpard,

\section{HEREDITY OR ENVIRONMENT ?}

GENETIC AND ENVIRONMENTAL FACTORS IN HUMAN ABILITY. Edited by J. E. Meade and A. S. Parkes. Oliver and Boyd, Edinburgh and London, 1966. Pp. 242. 57s. 6d.

This book is a symposium concerned with various problems of education. Some of these are more practical problems of the choice of methods and the selection of pupils; others are more theoretical problems of heredity and fertility. The authors do not claim that the conclusions they reach are new or divergent from one another or even closely connected with one another. Rather they hope to have improved slightly on their predecessors, whose methods they have applied but whose assumptions they have not too closely investigated.

Two of these papers, those of Vernon and Huntley, are of genetic interest, since they seriously broach the problem raised by the title, that of separating the effects of heredity and environment. Even they however have failed to examine their premises. There are two fundamental questions which ought to be discussed at the beginning:

(i) When we say that chromosomes of siblings, or of parents and offspring, are on an average half alike (as Fisher is said to have assumed in 1918 ) do we not need to take account of whether their 